\title{
The synergistic effect of cigarette taxes on the consumption of cigarettes, alcohol and betel nuts
} Jie-Min Lee*

Address: Department of Logistics Management, National Kaohsiung Marine University, N0.142, Hai-Chuan Rd. Nan-Tzu, Kaohsiung, Taiwan Email: Jie-Min Lee* - jmlee866@yahoo.com.tw

* Corresponding author

Published: 25 June 2007

BMC Public Health 2007, 7:121 doi:10.1 |86//47|-2458-7-121
Received: 27 January 2007

Accepted: 25 June 2007

This article is available from: http://www.biomedcentral.com/I47I-2458/7//2 I

(c) 2007 Lee; licensee BioMed Central Ltd.

This is an Open Access article distributed under the terms of the Creative Commons Attribution License (http://creativecommons.org/licenses/by/2.0), which permits unrestricted use, distribution, and reproduction in any medium, provided the original work is properly cited.

\begin{abstract}
Background: Consumption of cigarettes and alcoholic beverages creates serious health consequences for individuals and overwhelming financial burdens for governments around the world. In Asia, a third stimulant - betel nuts - increases this burden exponentially. For example, individuals who simultaneously smoke, chew betel nuts and drink alcohol are approximately 123 times more likely to develop oral, pharyngeal and laryngeal cancer than are those who do not.

To discourage consumption of cigarettes, the government of Taiwan has imposed three taxes over the last two decades. It now wishes to lower consumption of betel nuts. To assist in this effort, our study poses two questions: I) Will the imposition of an NT\$10 Health Tax on cigarettes effectively reduce cigarette consumption? and 2) Will this cigarette tax also reduce consumption of alcoholic beverages and betel nuts? To answer these questions, we analyze the effect of the NT\$10 tax on overall cigarette consumption as well as the cross price elasticities of cigarettes, betel nuts, and alcoholic beverages.
\end{abstract}

Methods: To establish the Central Bureau of Statistics demand function, we used cigarette, betel nut, and alcoholic beverage price and sales volume data for the years 1972-2002. To estimate the overall demand price elasticity of cigarettes, betel nuts, and alcoholic beverages, we used a seemingly unrelated regression analysis.

Results: We find that the NT $\$ 10$ health tax on cigarettes will reduce cigarette consumption by a significant $27.22 \%$. We also find that cigarettes, betel nuts, and alcoholic beverages have similar inherent price elasticities of $-0.657 \mathrm{I},-0.587 \mathrm{I}$, and $-0.626 \mathrm{I}$ respectively. Because of this complementary relationship, the NT $\$ 10$ health tax on cigarettes will reduce betel nut consumption by $20.07 \%$ and alcohol consumption by $7.5 \%$.

Conclusion: The assessment of a health tax on cigarettes as a smoking control policy tool yields a win-win outcome for both government and consumers because it not only reduces cigarette consumption, but it also reduces betel nut and alcoholic beverage consumption due to a synergistic relationship. Revenues generated by the tax can be used to fund city and county smoking control programs as well as to meet the health insurance system's current financial shortfall. 


\section{Background}

In Taiwan, as in countries around the world, cigarettes and alcohol pose many health threats. For instance, habitual smoking and excessive drinking can cause cardiovascular disease, digestive tract disease, hypertension and diabetes; they also increase the incidence of, and mortality from, many types of cancer [1-3]. Furthermore, studies have shown that alcohol abuse commonly leads to driving while intoxicated as well as to violent behavior $[4,5]$.

In addition to the well-known, detrimental effects of alcohol and cigarettes, a third stimulant - betel nuts - also poses a serious health threat in Taiwan. Betel nut use has long flourished throughout Asia [6-9]. In fact, it is estimated that roughly $10 \%-20 \%$ of the world's population uses it $[10,11]$. This means that betel nut consumption ranks fourth (behind cigarettes, alcoholic beverages, and coffee) on the list of the world's most widely used central nervous system stimulants $[12,13]$. In 2002, Taiwan's Bureau of Health Promotion took a nationwide survey and found that $17 \%$ of men and $1.2 \%$ of women habitually chew it [14].

Betel nut use is closely correlated with oral diseases, such as mouth cancer and fibrosis of the oral mucosa [15]. In Taiwan, deaths from oral cancer increased four-fold (from 349 to 1439) in the 15-year period between 1986 and 2001 , and the age-adjusted mortality rate more than doubled from 4.56 per 100,000 to 11.42 in the same time period. Oral cancer has now become the fifth-most prevalent cancer among Taiwanese males [16]. As a result of these and similar experiences around the world, the international medical community now believes that betel nuts are carcinogenic [17].

Individuals who simultaneously smoke, chew betel nuts, and drink alcohol are approximately 123 times more likely to develop oral, pharyngeal, and laryngeal cancer than are those who do not [15]. Unsurprisingly, many of the world's countries now consider control of the use and abuse of tobacco, alcohol, and betel nut as three of their major health priorities.

\section{Cigarette consumption}

The price of cigarettes in Taiwan is much lower than in many other countries, which has long made it difficult to significantly reduce the smoking population. If we take the average amount of work needed to purchase a pack of cigarettes as a proxy for cigarette purchasing power, then it would take an Indian 77 minutes of work, an Indonesian 62 minutes, a Chinese 56 minutes, and a Taiwanese only 7-10 minutes to purchase a pack of domestic cigarettes. In 2002, the country had more than 4.5 million smokers, which implies that one out of every three adults is a smoker [18].
Apart from the direct toll that smoking takes in sickness and loss of life, it is estimated that health problems derived from it add approximately NT $\$ 20$ billion annually to Taiwan's health insurance costs. It is also estimated that smoking reduced the GDP by more than US $\$ 1.032$ billion in 2000[19].

Raising taxes on cigarettes is currently one of the most effective and widely-used policies with which governments around the world control tobacco use [20-24]. The World Health Organization (WHO) has also proposed the use of taxes and other control measures to lower the consumption of tobacco [25]. The government of Taiwan took the first steps to adopt such a taxation policy in 1987 when it imposed an in-kind tax on cigarettes that increased the price by NT\$16.6 per pack [26]. After joining the World Trade Organization (WTO) in 2002, Taiwan imposed the Wine and Tobacco Tax Act, which added an excise tax of NT\$11.8 per pack. The act also included an additional Health \& Welfare tax of NT $\$ 5$ per pack.

Prior to this act, the price of cigarettes in Taiwan had remained constant for many years. Following its implementation, however, the price of domestic cigarettes rose by close to $30 \%$, and the price of a pack of cigarettes rose by roughly NT $\$ 10$ to an average of approximately NT $\$ 45$. This jump in cigarette prices caused consumption to fall from 2.31 billion packs in 2001 to 1.735 billion packs in 2002 [27]. The prevalence of smoking likewise fell - from $24.74 \%$ in 2001 to $23.53 \%$ in 2002; it fell again in 2003 to $22.84 \%$. This indicates that cigarette price increases do indeed reduce both cigarette consumption and the prevalence of smoking [28]. In 2006, the government increased the health tax on cigarettes from NT $\$ 5$ to NT $\$ 10$.

\section{Alcohol and betel nut taxes}

In addition to levying taxes on tobacco, Taiwan also taxes alcoholic beverages. Each liter of beer is subject to a tax of NT\$26, and each liter of distilled liquor is subject to a tax of NT\$185. Depending on alcohol content, reprocessed alcoholic beverages are taxed NT\$7 per each percent of alcohol when the alcohol content is less than $20 \%$ by volume and NT\$185 per liter when the alcohol content is over $20 \%$.

It should be noted that no health tax has yet been imposed on either alcohol or betel nuts. Furthermore, no excise tax has yet been imposed on betel nuts.

\section{Consumption trends of both betel nuts and alcoholic beverages}

Prior to 1987, consumption of betel nuts was negligible. However, between 1987 and 2001, the average retail price of betel nuts fell approximately $13.35 \%$ due to an oversupply. As a result, domestic consumption rose by $108 \%$, 
and average annual consumption in 2001 increased to 9.3 $\mathrm{kg}$ per person. The number of betel nut users likewise rose significantly. For example, in the southern counties of Taiwan, $9.8 \%$ of all adults and $22.5 \%$ of smokers, respectively, consumed betel nuts prior to 1987. By 2001, the rates had risen to $17.0 \%$ and $31.3 \%$ [29].

Consumption patterns of alcoholic beverages have also changed over the last decade. The average retail price of alcoholic beverages fell during the period of 1996-2001, while the consumption of alcoholic beverages remained flat, with average consumption staying at approximately 43 liters per person in 2001. As the price of alcoholic beverages fell, the prevalence of drinking rose. Among citizens over 15 years of age, $34 \%$ of men and $23 \%$ of women drank alcoholic beverages in 2002 [30,31].

\section{The goals of this study}

Over the last two decades, the government of Taiwan has attempted to discourage the consumption of cigarettes by imposing a series of taxes; in addition, discouraging consumption of betel nuts has now become one of its major health goals [32]. To assist in this effort, we began this study by posing two questions: 1) Will the imposition of an NT $\$ 10$ health tax on cigarettes effectively reduce cigarette consumption; and 2) Will this tax on cigarettes also lower consumption of alcoholic beverages and betel nuts?

Our questions are based on the premise that smoking, drinking, and chewing betel nuts are different types of consumer behavior; in physiological terms, alcohol and betel nuts are not as addictive as the nicotine found in tobacco. Yet the three habits are linked together because many people who consume one product also consume the others. Specifically, this study assessed the effect of the NT\$10 health tax imposed on each pack of cigarettes in 2006 on cigarette, betel nut, and alcoholic beverage consumption using the inherent price elasticity and the cross price elasticities of cigarettes-betel nuts and cigarettesalcoholic beverages. The study also sought to assess the cross effect of the health tax on consumption of betel nuts and alcoholic beverages.

The results of this study indicate that the NT $\$ 10$ health tax will not only reduce cigarette consumption, but it will also reduce betel nut and alcohol consumption. Such results provide an important reference with which to guide future decisions concerning health taxes imposed on cigarettes.

\section{An overview of cross price elasticity}

Because of the possible linkage between cigarettes, betel nuts, and alcoholic beverages in consumer decision-making, this study performed the simultaneous estimation of the price elasticity of all three products. Because it used the information contained in the residuals, this approach avoids estimation bias and yields better results than single equations do.

The chief basis for assessing the effect of cigarette taxes on cigarette consumption and on consumption of betel nuts and alcoholic beverages is the inherent price elasticity of cigarettes and the cross price elasticity of cigarette price elasticity relative to betel nuts and of cigarettes relative to alcoholic beverages. Past studies of the inherent price elasticity of cigarettes mostly obtained price elasticity values in the range of - $0.5 \sim-1.0$ for cigarettes in mid-/low-income countries and $-0.25 \sim-0.5$ in high-income countries [33]. Most literature on the price elasticity of cigarettes in Taiwan gives figures in the range of $-0.5 \sim-1.1$. This indicates that cigarette price hikes are more effective at reducing consumption in Taiwan than in higher income countries [34,35].

Literature on the cross price elasticity of cigarettes suggests that the cross price elasticities of cigarettes-alcoholic beverages and of cigarettes-betel nuts may be either negative or positive. Friend and Pagano (2005) showed that smokers whose cigarette consumption decreased were significantly less likely to revert to alcohol use than were those whose consumption increased or remained unchanged [36]. Most foreign estimates of the cross price elasticities of cigarettes-alcoholic beverages and cigarettes-betel nuts are in the range of $-0.5 \sim 1.0$ [37-41].

\section{Methods}

\section{Study design}

Price elasticities for cigarettes, betel nuts, and alcohol can be obtained statistically using a demand model. Demand for these products in Taiwan can be described using the Central Bureau of Statistics (CBS) (Keller and Van Driel, 1985) demand model [42], which, Lee et al. (2005) found to outperform other demand models in a comparative study [35]. The CBS demand model describes differential change in quantitative share as a function of changes in total cigarette, betel nut, and alcohol expenditures and prices:

$$
w_{i, t}\left(d \log q_{i, t}-d \log Q_{t}\right)=c_{i} d \log Q_{t}+\sum_{j} s_{i, j} d \log p_{j, t}
$$

Where $q_{i, t}$ and $p_{j, t}$ are the quantity and the price of the $i^{\text {th }}$ good during period $t, w_{i, t}$ is the budget share of the $i^{\text {th }}$ good during period $t$, and $d \log Q_{t}=\sum_{i} w_{i, t} d \log q_{i, t}$ is the Divisia quantity index. The parameter $c_{i}$ denotes marginal budget share, while the parameter $s_{i j}$ measures the cross substitution effects of a compensated change in the price of $j$ on the quantity of $i$. The theory of demand implies the 
following adding-up, symmetry, and homogeneity restrictions on the CBS parameters in equation (1). Finally, the Marshallian own-price and expenditure elasticities, respectively $e_{i i}$ and $\eta_{i}$, can be derived from equation (1) as follows: $e_{i i}=\left(s_{i i} / \mathrm{w}_{i}+c_{i}\right)-w_{i}$ and $\eta i=\left(c_{i} / w_{i}\right)+1$. We calculated potential reductions in cigarette, betel nut, and alcohol consumption after levying the NT $\$ 10$ tobacco health tax by multiplying price elasticity by the percentage of the price change. In this study, the CBS model constrained by homogeneity and symmetry conditions was implemented with Zellner's Seemingly Unrelated Regression (SUR) procedure using the Time Series Processor package (TSP), version $4.2 \mathrm{~B}$.

\section{Data}

We used aggregate time series data for the period from 1972 through 2002 to analyze consumer demand for cigarettes, betel nuts, and alcohol. Data on cigarette and alcohol sales in Taiwan were obtained from the Taiwan Tobacco and Wine Monopoly Bureau (1972-2000) and National Treasury Agency (2001-2002) [43,27]. Because we could not obtain the real sales data for betel nuts, we have had to use production data of betel nuts for the period of 1972-2002, chiefly obtained from the ROC (Republic of China) Agricultural Statistics Yearbook, to calculate betel nut consumption [44]. It should be noted that the import of betel nuts is currently prohibited in Taiwan and that most betel nuts produced in the country are for domestic consumption, not export.

Cigarette, betel nut and alcohol consumption was calculated as the annual per capita number of packs of cigarettes, betel nuts, and alcoholic beverages sold to users 15 years of age or older. Annual per capita cigarette, betel nut and alcohol consumption by users 15 years of age or older was calculated by dividing total annual consumption by the year-end population of adults 15 years of age or older. (Note that cigarettes include both domestic and imported brands.) The total expenditures were classified as those on domestic cigarettes, imported cigarettes, betel nuts, wine, beer, and spirits. The year-end data for adults 15 years of age or older used in this study were obtained from the Ministry of the Interior's 2003 Statistical Yearbook of Interior [45].

Cigarette retail price data from 1972 to 2002 consisted of the average retail price per pack weighted by the quantity of each brand of cigarettes sold in Taiwan. Cigarette retail price data from 2001 to 2002 was obtained from the Taiwan Interview Survey on Cigarette Consumption (TISCC) (Tsai, 2005) [28]. The farm price of betel nuts was calculated as the betel nut production value divided by betel nut production quantity. All betel nut retail prices were derived by adding sales margin to betel farm prices. They are based on data from the Taiwan Agricultural Prices and Costs Monthly and the Taiwan Statistical Yearbook [46]. The price of alcohol was derived by dividing the total sales income of alcohol by total sales quantity of consumed alcohol. All cigarette, betel nut, and alcohol prices were deflated using the Consumer Price Index (1996).

\section{Results \\ Elasticity of cigarette demand}

Table 1 shows that estimated own price elasticity coefficients for cigarettes, alcohol, and betel nuts are -0.6517, 0.5871 and -0.6261 respectively. All of the own price elasticities (diagonal elements in Table 1) are negative and are statistically significant at a five percent level. All goods have own price elasticities greater than 0.5 . This is a clear indication that consumption of cigarettes, alcohol, and betel nuts in Taiwan does respond to a change in price, although proportionate increases in price lead to a slightly less than proportionate reduction in consumption.

Analysis of cross-price elasticities suggests the nature of the relationship between two products and indicates whether they are mutually substitutive or complementary. It implies, for instance, that betel nuts and cigarettes are complementary if cross-price elasticities for betel nuts are negative. Taking betel nuts as an example, the respective cross-price elasticity of -0.484 for cigarettes implies that demand for betel nuts is more sensitive to changes in the price of cigarettes. This figure implies that a $10 \%$ increase in the price of cigarettes will cause a $4.84 \%$ decrease in the price of betel nuts. Taking cigarettes as an example, demand for cigarettes is sensitive to changes in the price of alcohol (-0.2503), but less sensitive to changes in the price of betel nuts (-0.1041). This suggests that a change in the price of alcoholic beverages may cause more than double the change in the consumption of cigarettes when compared to the same change in the price of betel nuts.

\section{Effects of price changes due to taxation}

This study used cigarette, betel nut, and alcoholic beverage consumption information for 2001 as baseline data to analyze the effect of two health tax increases on cigarette consumption, as well as the effect of the NT $\$ 10$ health tax imposed on each pack of cigarettes in 2006, on the consumption of alcoholic beverages and betel nuts. The results of the calculations are shown in Table 2. Note that in 2001, average annual cigarette consumption in Taiwan was 126.35 packs per capita, and the average retail price was approximately NT $\$ 36$ per pack. The price of cigarettes rose NT $\$ 15$ (approximately 41.47\%) after imposition of the NT $\$ 10$ Health Tax in 2006.

According to this study's estimated cigarette price elasticity of -0.6517 , the NT $\$ 10$ Health Tax will cause average 
Table I: Estimated price and expenditure elasticity values ${ }^{\mathbf{a}}$

\begin{tabular}{|c|c|c|c|c|c|}
\hline \multirow[t]{2}{*}{ Item } & \multirow[t]{2}{*}{ Budget share } & \multirow[t]{2}{*}{ Expenditure } & \multicolumn{3}{|l|}{ Prices } \\
\hline & & & Cigarettes & Alcohol & Betel nuts \\
\hline & & 1.0062 & -0.6517 & -0.2503 & -0.1041 \\
\hline \multirow[t]{3}{*}{ Cigarettes } & 0.439 & & & & \\
\hline & & $(4.708)^{* *}$ & $(-6475)^{* *}$ & $(-2.842)^{* *}$ & $(-2.526)^{* *}$ \\
\hline & & 0.8104 & -0.1881 & $-0.587 \mid$ & -0.0351 \\
\hline \multirow[t]{3}{*}{ Alcohol } & 0.401 & & & & \\
\hline & & $(2.433)^{* *}$ & $(-1.247)$ & $(-4.407)^{* *}$ & $(-0.546)$ \\
\hline & & 1.4578 & -0.4840 & -0.3476 & -0.6261 \\
\hline \multirow[t]{2}{*}{ Betel nuts } & 0.160 & & & & \\
\hline & & $(1.116)$ & $(-0.857)$ & $(-0.857)$ & $(-2.48 \mathrm{I})^{* *}$ \\
\hline
\end{tabular}

Notes: $t$ ratios are shown in parentheses.

a. Marshallian own-price elasticities

** Statistically significant at $5 \%$ level

per capita cigarette consumption to fall by 34.37 packs (approximately $27.22 \%$ ), reducing national cigarette consumption by roughly 610 million packs annually and reducing medical expenditures by around 16.01\%[47]. Based on a prevalence elasticity of cigarette demand of 0.15 estimated by the U.S. Centers for Disease Control and Prevention (CDC 1998) [48] and a $41.47 \%$ increase in the price of cigarettes, the NT $\$ 10$ Health Tax will cause the prevalence of smoking to fall by $6 \%$. With 3.9 million smokers in Taiwan, this implies that 234,000 people will quit smoking as the result of this tax increase. Using the estimated epidemiological analysis reported by the World Bank [49], approximately 58,500 lives will be saved due to its implementation.

In sum, a cigarette tax increase in Taiwan has the potential to substantially reduce the number of smokers, the amount of tobacco consumed, and the costs of smokingrelated illnesses and premature death.

\section{Effects on alcohol and betel nut consumption}

On average, Taiwanese consumed $9.303 \mathrm{~kg}$ of betel nuts and 42.93 liters of alcoholic beverages in 2001. The average retail price of betel nuts and alcoholic beverages at that time was NT\$300 per kilogram and NT\$88.58 per liter respectively. Employing an estimated cigarette price elasticity relative to betel nuts of -0.484 and a cigarette price elasticity relative to alcoholic beverages of -0.1881 , this study calculates that the NT\$10 health tax on cigarettes will cause per capita betel nut and alcoholic beverage consumption to fall by $20.07 \%$ and $7.5 \%$ respectively, reducing total annual betel nut and alcoholic beverage consumption by 33.13 million kilograms and 51.13 million liters. We estimate that this reduction in betel nut consumption will lessen medical expenditures by roughly $0.89 \%$ (see Table 2).

\section{Discussion}

This study finds that imposition of the NT\$10 Health Tax on cigarettes in 2006 will reduce cigarette consumption in Taiwan by a very significant $27.22 \%$. This figure approximates statistics from the National Treasury, which reported in 2006 that cigarette sales had fallen by $28.63 \%$ [27].

The study also finds that a complementary relationship does exist among the three stimulants. Thus, in addition to reducing cigarette consumption, the NT\$10 health tax on cigarettes will also reduce betel nut and alcoholic beverage consumption as well as the incidence of disease caused by these products. Conversely, increasing taxes on alcoholic beverages and levying a health tax on betel nuts would help to reduce cigarette consumption while also lowering alcohol and betel nut consumption.

Table 2: Effects of health taxes on cigarette (betel nut) consumption and tax revenues

\begin{tabular}{|c|c|c|c|c|c|}
\hline Effect on & Change in price (\%) & $\begin{array}{c}\text { Change in } \\
\text { consumption (\%) }\end{array}$ & $\begin{array}{l}\text { Change in Consumption } \\
\text { (million packs/million kg) }\end{array}$ & $\begin{array}{l}\text { Cigarette or betel nut use } \\
\text { elasticities relative to medical costs* }\end{array}$ & $\begin{array}{l}\text { Medical cost } \\
\text { savings (\%) }\end{array}$ \\
\hline \multicolumn{6}{|c|}{ Tax scenarios: Additional Health tax of NT\$10 } \\
\hline Cigarettes & 41.47 & -27.22 & -609.8 & 0.5885 & 16.01 \\
\hline Alcohol & - & -7.50 & -51.13 & - & - \\
\hline Betel nuts & - & -20.07 & -33.13 & 0.0443 & 0.89 \\
\hline
\end{tabular}

* All values are quoted from the estimates of Lee (2004) [47]. 
When surtaxes have been imposed on the three addictive products, a synergistic effect will arise since each tax will actually reduce consumption of all three products. Due to the complementary relationship between smoking and betel nut use, betel nut control policy should be linked with tobacco control policy when increasing cigarette taxes. Doing so will help to curb the current rapid growth in betel nut consumption.

We conclude from this that the government should continue using cigarette taxes as a tool with which to reduce cigarette consumption. The health tax on cigarettes will not only substantially reduce cigarette consumption, but it will also make a fiscal contribution to the government. For example, it will greatly lessen the health hazards associated with such stimulants and ultimately help to achieve the goal of disease prevention. It will also encourage young smokers and smokers who are not heavily addicted to curtail their cigarette consumption, which is a primary goal of the government's tobacco control policy. Higher cigarette prices will hopefully dissuade young people from acquiring a smoking habit in their youth. (To achieve even greater success in the campaign against smoking, the government should also ensure that antismoking education is provided in the schools.)

\section{Recommendations}

According to the results of this study, an NT $\$ 10$ health tax on each pack of cigarettes will cause average per capita cigarette consumption to fall by approximately 34.37 packs annually, reduce Taiwan's cigarette consumption to 1.703 billion packs (calculated on the basis of the population over 15 years of age in 2005), boost government cigarette tax revenue to NT $\$ 37.118$ billion, and increase the health tax on cigarettes to NT $\$ 17.03$ billion. Ten percent of the increase in health tax revenue (NT\$1.703 billion) could be used for smoking control, public health, and social welfare, while the remaining 90\% (NT\$15.327 billion) could be used to make up the current health insurance deficit. A health tax on cigarettes thus promotes social fairness and alleviates the regressive nature of cigarette taxes. As long as cigarette prices increase faster than cigarette consumption falls, the government's revenue from cigarette taxes will rise, thereby helping to fill the health insurance system's current financial shortfall. In sum, the use of health taxes on cigarettes as an anti-smoking policy tool is indeed effective and persuasive.

\section{The need for a health tax on alcoholic beverages and betel nuts}

To date Taiwan has yet to levy any health taxes on betel nuts and alcoholic beverages. Were it to do so, the government could achieve much greater health and economic gains due to the close inherent price elasticities of cigarettes, betel nuts and alcoholic beverages and the comple- mentary relationship between them. Therefore, we recommend the following:

Relevant laws should be amended so as to require wholesalers to collect a health tax on betel nuts. This strategy would have three advantages. First, the relatively low number of wholesalers will make it easy to keep track of and promote administrative efficiency. Second, since the wholesale level is the biggest beneficiary of the betel nut industry, taxing wholesalers will be relatively fair and free of dispute. Third, wholesalers can easily pass the cost of the health tax on to consumers, which will achieve the policy goal of reducing betel nut intake.

In the case of alcoholic beverages, a health tax should be imposed using the same approach as that adopted for cigarettes. Revenue generated from health taxes on betel nuts and alcoholic beverages could be transferred to the National Health Insurance reserve fund or used to defray the cost of betel nut and drinking control measures. Health taxes would help to compensate for the additional costs to the health insurance system caused by use of these products; they would also provide additional funding for betel nut and drinking control efforts.

\section{Conclusion}

This study finds that cigarettes, betel nuts, and alcoholic beverages are mutually complementary; from the point of view of effects on health, these products typically exert a negative synergistic effect. Therefore, they should not be seen as separate influences. Since most betel nut users in Taiwan smoked and drank before using betel nuts, smoking and drinking can be seen as the main gateways to betel nut use.

In light of this, reducing smoking and drinking rates is the first step to lowering betel nut consumption. Conversely, reducing consumption of alcohol and cigarettes is an effective strategy with which to reduce betel nut consumption. Since the unhealthy behaviors of smoking, chewing betel nuts, and drinking typically occur together, public health authorities should develop effective health promotion programs that reflect this linkage and thereby significantly improve citizen health.

\section{Competing interests}

The author(s) declare that they have no competing interests.

\section{Authors' contributions}

$\mathrm{JM}$. Lee is the sole author.

\section{Acknowledgements}

Part of this research was support by extramural grants from the National Science Council of the Executive Yuan (executive branch of the Republic of China) (95-24I5-H-022-00I). 


\section{References}

I. Chun BY, Dobson AJ, Heller RF: Smoking and the incidence of coronary heart disease in an Australian population. Med J Aust 1993, I 59:508-5I2.

2. Choi SY, Kahyo H: Effect of cigarette smoking and alcohol consumption in the etiology of cancers of the digestive tract. Int J Cancer I99I, 49:381-386.

3. Uchumoto S, Tsumura K, Hayashi T, Suematsu C, Endo G, Fujii S, Okada K: Impact of cigarette smoking on the incidence of Type 2 diabetes mellitus in middle-aged Japanese men: the Osaka Health Survey. Diabet Med 1999, I 6:95I-955.

4. Markowitz S, Grossman M: Alcohol regulation and domestic violence towards children. Contemp Econ Policy 1998 , I 6(3):309-320.

5. Markowitz S: The role of alcohol and drug consumption in determining physical fights and weapon carrying by teenagers. East Econ J 200I, 27(4):409-432.

6. Yang IH: Epidemiological studies on areca quid and oral cancer, Literature Review Series Taipei: National Health Research Institutes; 2000.

7. Warnakulasuriya S, Trivedy C, Peters T: Areca nut use: an independent risk factor for oral cancer: The health problem is under-recognised. Brit Med J 2002, 324:799-800.

8. Winstock A: Areca nut symposium: areca nut-abuse liability, dependence and public health. Addict Biol 2002, 7:133-138.

9. Gupta PC, Warnakulasuriya S: Areca nut symposium: global epidemiology of areca nut usage. Addict Biol 2002, 7:77-83.

10. Raghavan V, Baruah HK: Areca nut: India's popular masticatory -history, chemistry and utilization. Econ Bot 1958, I 2:3 I 5-345.

II. Marshall M: An overview of drugs in Oceania. In Drugs in Western Pacific Societies: Relations of Substance Edited by: Lindstrom L. Lanhan, Md: University Press of America; 1987: 13-50.

12. Cawte J: Psychoactive substances of the South Seas: betel, kava and pituri. Aust Nz J Psychiat 1985, 19:83-87.

13. Norton SA: Betel: consumption and consequences. J Am Acad Dermatol 1997, 37:|3-50.

14. Department of Health, Executive Yuan: Report of Knowledge, Attitude and Practice (KAP) in Health Promotion in Taiwan. Taichung 2003.

15. Ko YC, Huang YL, Lee CH, Chen MJ, Lin LM, Tsai CC: Betel quid chewing, cigarette smoking and alcohol consumption related to oral cancer in Taiwan. J Oral Pathol Med 1995, 24:450-453.

16. Wen CP, Cheng TY, Eriksen MP: How opening the market for cigarettes led to an increase in betel quid use in Taiwan. Public Health 2005, I I 9( I 0):940-944.

17. Department of Health, Executive Yuan: Cancer Registry Annual Report. Taipei 2001.

18. Wen CP, Levy DT: Smoking policy at the crossroads: opportunities and challenges. In Collection of Research Papers on Tobacco or Health in Taiwan Edited by: Wen CP, Tsai SP, Chen Ted TL, Shih YT. Taipei: Division of Health Policy Research, National Health Research Institutes; 2002:4-49.

19. Tsai SP, Wen CP, Hu SC, Cheng TY, Huang SJ: Workplace smoking related absenteeism and productivity cost in Taiwan. Tob Control 2005, I 4(SuppI I):i33-37.

20. US Dept of Health and Human Services: Reducing Tobacco Use: A Report of the Surgeon General. Atlanta 2000.

21. Sung HY, Hu TW, Keeler TE: Cigarette taxation and demand: an empirical model. Contemp Econ Policy 1994, I 2(3):91-100.

22. Hu TW, Sung HY, Keeler TE: Reducing cigarette consumption in California: tobacco taxes vs. anti-smoking media campaign. Am J Public Health 1998, 88: I218-1222.

23. Lanoie $P$, Leclair P: Taxation or regulation: looking for a good anti-smoking policy. Econ Lett 1998, 58:85-89.

24. Hu TW, Mao Z: Effects of cigarette tax on cigarette consumption and the Chinese economy. Tob Control 2002, I I: I05-108.

25. World Health Organization: The W H R 1999: Making a Difference. Geneva 1999.

26. Hu TW: Cigarette taxation in China: Lessons from international experiences. Tob Control 1997, 6: I36-140.

27. National Treasury Agency, Ministry of Finance: Statistics on Tobacco and Wine. Taipei 2006.

28. Tsai YW: Analysis of "Tobacco and alcohol tax law" and it's impact on cigarette Taipei,: Department of Health, Executive Yuan; 2005.

29. Wen CP: The Taiwan tobacco atlas Taipei: United Medical Foundation and National Health Research Institutes; 2004:38-39.
30. Department of Health, Executive Yuan: Survey of the Health Promotion Knowledge, Attitudes, and Behavior of Taiwan Citizens. Taipei 2003

31. Liang CY, Chou TM, Ho PS, Shieh TY, Yang YH: Prevalence Rates of Alcohol Drinking in Taiwan. Taiwan Journal of Oral Medicine \& Health Sciences 2001, 20(2):91-104.

32. Department of Health, Executive Yuan: Cancer Registry Annual Report. Taipei; $200 \mathrm{I}$ and 2005

33. Chaloupka FJ, Hu TW, Warner KE: The taxation of tobacco products. In Tobacco Control in Developing Countries Edited by: Jha $\mathrm{P}$. Chaloupka FJ. London: Oxford University Press; 2000:237-272.

34. Hsieh CR, Hu TW, Lin CFJ: The demand for cigarettes in Taiwan: domestic versus imported cigarette. Contemp Econ Policy 1999, 17:223-234.

35. Lee JM, Liao DS, Ye CY, Liao WC: Effect of cigarette tax increase on cigarette consumption in Taiwan. Tob Control 2005, I 4(Suppl I):i7 I-75.

36. Friend $\mathrm{KB}$, Pagano ME: Changes in cigarette consumption and drinking outcomes : findings from Project MATCH. J Subst Abuse Treat 2005, 29(3):221-229.

37. Bask M, Melkersson M: Rationally addicted to drinking and smoking? Appl Econ 2004, 36:373-38I.

38. Decker SL, Schwartz AE: Cigarette and alcohol: Substitutes or Complements? Cambridge, MA: National Bureau of Economic Research; 2000.

39. Fanelli LM, Mazzocchi M: Back to the future? Habits and forward-looking behaviour for UK alcohol and tobacco demand MIMEO: Universita degli Studi Bologna; 2004.

40. Jimenez S, Labeaga JM: Is it possible to reduce tobacco consumption via alcohol taxation? Health Econ 1994, 3:23 I-24I.

41. Jones AM: A system approach to the demand for alcohol and tobacco. Bullettin of Economic Research 1989, 4 I(2):85- I I I.

42. Keller WJ, Van Driel J: Differential consumer demand analysis. Eur Econ Rev 1985, 27:375-390.

43. Taiwan Tobacco and Wine Monopoly Bureau (TTWMB): Tobacco and Wine Statistical Yearbook. Taipei 197I.

44. Council of Agriculture, Executive Yuan: Agricultural Statistics Yearbook. Taipei 2004.

45. Ministry of the Interior of the Republic of China: Statistical Yearbook of Interior Taipei 2003.

46. Council of Agriculture, Executive Yuan: Taiwan Agricultural Prices and Costs Monthly. Taipei 2004.

47. Lee JL: The feasibility of leveying ear-marked tax on betel nuts in Taiwan 2004 [http://grbsearch.stpi.org.tw/GRB/]. Taipei: Department of Health, Executive Yuan

48. Farrelly MC, Bray JW: Response to increases in cigarette prices by race/ethnicity, income and age groups - United States 1976-1993. Morb Mortal Wkly Rep 1998, 47:605-609.

49. World Bank: Curbing the Epidemic: Governments and the Economics of Tobacco Control 1999 [http://wwwl.worldbank.org/tobaccol reports.htm]. Washington, DC: World Bank, Development in Practice Series

\section{Pre-publication history}

The pre-publication history for this paper can be accessed here:

http://www.biomedcentral.com/1471-2458/7/121/pre pub 